\title{
A temática ambiental nos projetos de pesquisa e extensão do curso de jornalismo das universidades do Piauí
}

Elinara Soares Barros de Sousa

Mestre em Desenvolvimento e Meio Ambiente pela Universidade Federal do Piaui (UFPI), jornalista, pesquisadora e secretária executiva da UFPI.

E-mail: elinarabarros@ufpi.edu.br

Denis Barros de Carvalho

Professor doutor e pesquisador do Mestrado em Desenvolvimento e Meio Ambiente da Universidade Federal do Piaui (UFPI) e vinculado ao Departamento de Fundamentos da Educação da UFPI.

E-mail: denispsi@bol.com.br

Orlando Maurício de Carvalho Berti

Professor doutor do Departamento de Comunicação Social da Universidade Estadual do Piauí (Uespi) e vice-presidente da Rede Brasileira de Mídia Cidadã.

E-mail: orlandoberti@yahoo.com.br

Resumo: Esta pesquisa analisa como a temática ambiental aparece nos projetos de pesquisa e extensão elaborados pelos docentes dos cursos de jornalismo das duas universidades públicas piauienses: Universidade Estadual do Piauí (Uespi) e Universidade Federal do Piauí (UFPI). Para tanto, pesquisou-se a produção dos professores nesses dois eixos e percebeu-se que há lacunas na formação dos jornalistas nessas duas universidades, não só quanto à questão ambiental como a outras temáticas e possibilidades existentes aos alunos nos eixos pesquisa e extensão. Percebeu-se ainda a necessidade de interferência da gestão superior em incentivar maior produção, principalmente de projeto de extensão nas duas instituições.
Abstract: This study aims to analyze how the environmental theme appears in research and extension projects elaborated by Journalism qualification courses' professors of public universities in Piauí, Brazil: State University of Piauí (Uespi) and Federal University of Piauí (UFPI). Thus, we investigated project production of professors in both institutions, and noticed that there are gaps in the training of journalists of these universities, not only on the environmental issue but also on other topics and opportunities available to students in research and extension fronts. We also noticed the need of interference of superior management in encouraging greater production, mainly of extension projects in the academy. 
Nota-se que, apesar dessas constatações, a questão ambiental está contemplada no currículo dos cursos de jornalismo no país como tema transversal.

Palavras-chave: meio ambiente; jornalismo; pesquisa; extensão; Piauí.
It is noteworthy that, despite these findings, environmental issues are included in the curriculum of Journalism courses in Brazil as a cross-cutting theme.

Keywords: environment; Journalism; research; extension; Piauí.

\section{INTRODUÇÃO}

As universidades exercem papel de suma importância na sociedade pela transmissão e construção de conhecimentos, em que há socialização de ideias e ideais envolvendo pesquisas, extensões e, notadamente, ensino. Com isso, a principal função da academia é a de formação de profissionais qualificados para atuar em diversas áreas, além de dar formação cidadã, na qual são consideradas não apenas questões técnicas de cada profissão, mas a atitude do ser humano na sociedade. A universidade é lugar-chave para o preenchimento das lacunas causadas por um processo educativo deficiente ${ }^{1}$.

Uma universidade ambientalmente responsável é capaz de modificar a

1. MARCOMIN, Fátima Elizabeti; SILVA, Alberto Dias Vieira. A universidade sustentável: alguns elementos para a ambientalização do ensino superior a partir da realidade brasileira. In: CONGRESSO INTERNACIONAL DE EDUCAÇÃO AMBIENTAL DOS PAÍSES LUSÓFONOS E GALICIA, 1., 2007, Santiago de Compostela. Anais... Santiago de Compostela: Ceida, 2007, p. 1-16.

2. Ibidem.

3. RAMOS, Roberto. A educação e o conhecimento: uma abordagem complexa. Educar, Curitiba, n. 32, p. 75-86, 2008.

4. MORAES, Maria Cândida. O paradigma educacional emergente. 16. ed. Campinas: Papirus, 2011, p. 43.

5. MORIN, Edgar. Os sete saberes necessários à educação do futuro. 8. ed. São Paulo: Cortez, 2003, p. 40. sociedade e proporcionar uma economia social mais sustentável, buscando preservar os limites ambientais e éticos da liberdade de mercado². Diante disso, percebe-se a importância da inclusão dessa temática durante a formação profissional de forma interdisciplinar e contextualizada e não como tema dissociado da realidade dos discentes.

Quando se fala em construção do conhecimento em que o objeto é afastado do sujeito, o que se percebe é uma fragmentação que apreende partes em detrimento do todo. Isso "torna a Educação esquizofrenizada em partes, sendo disciplinas que se isolam, nas quais o Conhecimento, de características racionais e objetivas, dá conta da ordem, mas não dá conta da desordem"”. E é justamente a desordem que necessita ser analisada, pois o conhecimento humano não se dá somente no equilíbrio, mas em situações de caos.

A ênfase dada ao pensamento cartesiano é criticada, pois tal concepção acabou provocando a fragmentação do pensamento, que "direcionou a nossa educação à supervalorização de determinadas disciplinas acadêmicas, à super-especialização, uma vez que todos os fenômenos complexos, para serem compreendidos, necessitam ser reduzidos às suas partes constituintes"4.

Morin salienta a necessidade de uma reforma do pensamento, pois é insuficiente o conhecimento realizado a partir de fragmentos isolados, sem situar os dados em um contexto. O autor defende ainda que "as mentes formadas pelas disciplinas perdem suas aptidões naturais para contextualizar os saberes, do mesmo modo que para integrá-los em seus conjuntos naturais”. 
Morin $^{6}$ destaca o pensamento complexo que é "capaz de reunir (complexus: aquilo que é tecido conjuntamente), de contextualizar, de globalizar, mas, ao mesmo tempo, capaz de reconhecer o singular, o individual, o concreto". Ou seja, o importante é uma visão do conjunto. O autor explica que não defende a substituição do conhecimento das partes pelo da totalidade, mas a conjugação dos dois conhecimentos.

É necessário mais do que uma única forma de obter conhecimento para que se tenha diversas visões do mesmo objeto; além disso, o conhecimento produzido é consequência de um modelo dominante adotado pela sociedade. No entanto, não significa que exista somente uma forma "correta" da produção desse conhecimento, é preciso ampliar o campo de visão e trazer o objeto pesquisado para o contexto em que se encontra, buscando destacar suas características próprias.

O que se defende é uma mudança na percepção do conhecimento produzido que leva em consideração o meio ambiente. Leff traz a noção de um saber ambiental diretamente ligado à "desconstrução do conhecimento disciplinar, simplificador, unitário [...] É a negação das certezas insustentáveis e a aventura na construção de novos sentidos de ser"7. O autor destaca a simplificação do conhecimento pois abrange a complexidade da sociedade e defende a racionalidade ambiental.

A problemática ambiental surgiu como resultado de uma crise da racionalidade econômica que prevaleceu durante a modernização, pois os limites da natureza não são tidos como importantes ${ }^{8}$. Por considerar irracional o modelo capitalista e seu padrão de produção e de consumo, o autor afirma que a crise ambiental surge para questionar paradigmas até então dominantes que legitimaram o crescimento econômico e negaram a natureza.

Ao relacionar jornalismo e temática ambiental, Campos ${ }^{9}$ afirma que há responsabilidade por parte do jornalista para a obtenção de um ambiente sustentável, mas também é necessário que haja "uma responsabilidade social da área acadêmica que tem a missão de preparar melhor os jornalistas que vão tratar da questão ambiental. Do contrário, eles chegarão despreparados aos seus locais de trabalho".

A Resolução CNE/CES no 1 , de 27 de setembro de $2013^{10}$, que estabelece as novas diretrizes curriculares nacionais para o curso de graduação em jornalismo, foi publicada em 2013 e traz como uma das competências gerais do profissional da área a compreensão e valorização, a partir de uma perspectiva histórica e social, do desenvolvimento sustentável. Em decorrência disso, a organização dos currículos deve contemplar no projeto pedagógico do curso seis eixos de formação: fundamentação humanística, fundamentação específica, fundamentação contextual, formação profissional, aplicação processual e prática laboratorial. O desenvolvimento sustentável é trazido como item a ser considerado no eixo de fundamentação humanística.

Além de competências gerais, as diretrizes trazem competências cognitivas, pragmáticas e comportamentais que os profissionais de jornalismo devem ter.
6. Idem. O pensamento complexo, um pensamento que pensa. In: MORIN, Edgar; LE MOIGNE, Jean-Louis. A inteligência da complexidade. São Paulo: Peirópolis, 2000, p. 197-213.

7. LEFF, Enrique. Saber ambiental: sustentabilidade, racionalidade, complexidade, poder. 8. ed. Petrópolis: Vozes, 2012, p. 21.

8. MORAES, Maria Cândida, op. cit.

9. CAMPOS. Pedro Celso. Meio Ambiente: a sustentabilidade passa pela educação (em todos os níveis, inclusive pela mídia). Em Questão, Porto Alegre, v. 12, n. 2 , p. 387-419, jun./dez. 2006, p. 413-414. Disponível em: <http:// seer.ufrgs.br/EmQuestao/ article/view/42/14>. Acesso em: 27 fev. 2017.

10. BRASIL. Ministério da Educação. Conselho Nacional de Educação. Resolução $n^{\circ} 1$ de 27 de setembro de 2013. Institui as Diretrizes Curriculares Nacionais para o curso de graduação em Jornalismo, bacharelado, e dá outras providências. Diário Oficial da União, Brasília, DF, $1^{\circ}$ out. 2013. Seção 1, p. 26. Disponível em: <http:// portal.mec.gov.br/index. php?option=com_docman\&view=download\&alias=14242-rces001-13\&category_slug=setem bro $=2013--p d f \& \mid$ temid30192http>. Acesso em: 20 mar. 2017. 
Nestas últimas, o documento destaca o comportamento voltado ao papel social de defensor da sociedade do jornalista:

e) atentar para os processos que envolvam a recepção de mensagens jornalísticas e o seu impacto sobre os diversos setores da sociedade; f) impor aos critérios, às decisões e às escolhas da atividade profissional as razões do interesse público; g) exercer, sobre os poderes constituídos, fiscalização comprometida com a verdade dos fatos, o direito dos cidadãos à informação e o livre trânsito das ideias e das mais diversas opiniões ${ }^{11}$.

Diante do contexto apresentado e frisado, foi realizada pesquisa buscando perceber como se dá a formação de jornalistas nas universidades públicas do Piauí quanto à temática ambiental.

Com base nos dados obtidos, buscou-se analisar neste artigo as informações sobre os eixos pesquisa e extensão, por entender que são importantes para a formação desses profissionais.

\section{METODOLOGIA}

Esta pesquisa foi realizada utilizando como método uma abordagem qualiquantitativa baseada em pesquisa de campo e levantamento dos projetos de pesquisa e extensão realizados pelos professores do departamento de comunicação social da Universidade Federal do Piauí (UFPI) e da coordenação do curso de Comunicação Social dos dois campi da Universidade Estadual do Piauí (Uespi).

Primeiramente buscou-se informações nas pró-reitorias responsáveis (pró-reitoria de Pesquisa e pró-reitoria de Extensão na UFPI; e pró-reitoria de pesquisa e pós-graduação e pró-reitoria de extensão, assuntos estudantis e comunitários na Uespi). Na UFPI foram obtidas somente informações quantitativas dos projetos cadastrados e na Uespi não ocorreu disponibilização de dados sobre os projetos cadastrados.

Em seguida, foram solicitadas informações no departamento de comunicação social da UFPI e na coordenação de comunicação social da Uespi, porém não se obteve dados sobre a produção dos professores. Diante desse contexto, foi necessária a complementação dos dados através de informações contidas nas páginas dos cursos na internet e, no caso específico da UFPI, na página de docentes do Sistema Integrado de Gestão de Atividades Acadêmicas (SIGAA). Além disso, utilizaram-se informações dos currículos Lattes dos professores lotados nos cursos.

Estabeleceu-se os seguintes critérios de análise dos projetos de pesquisa e extensão: projetos em vigor ou concluídos que tiveram como coordenador do projeto professor lotado no departamento de comunicação social da UFPI ou coordenação de comunicação social da Uespi. Após a conclusão da coleta de dados, foram analisadas as informações obtidas e realizadas discussões que levaram em consideração as referências bibliográficas. 


\section{RESULTADOS DA PESQUISA}

\subsection{Universidade Federal do Piauí}

Durante a existência do curso de jornalismo da UFPI percebeu-se avanço na área no Piauí e maior interesse em pesquisa, justamente por ser o primeiro curso de formação superior em jornalismo do estado. Com a necessidade de buscar qualificação na área, os professores lotados no departamento de comunicação social precisaram sair do estado para realizar mestrado e doutorado.

Após a qualificação dos docentes e com o aumento na quantidade de pesquisas, a UFPI conseguiu aprovar no Conselho de Ensino, Pesquisa e Extensão (CEPEX) através da Resolução no 113, de 28 de junho de 2010, o programa de mestrado acadêmico em comunicação, recomendado pelo Conselho Técnico-Científico de Educação Superior (CTC-ES) da Coordenação de Aperfeiçoamento de Pessoal de Nível Superior (CAPES) em 2011.

Na UFPI, os projetos de pesquisa executados pelos professores devem ser cadastrados pela pró-reitoria de pesquisa (PROPESQ). Durante a pesquisa, buscou-se informações na página oficial da coordenadoria-geral de pesquisa (CGP), órgão vinculado à pró-reitoria, na qual são publicados os títulos de todos os projetos cadastrados pelos departamentos que compõem a instituição de ensino superior (IES).

No entanto, o cadastramento no setor responsável não significa que o projeto foi efetivado, pois o artigo $\mathrm{n}^{\mathrm{o}} 121$ do regimento geral da UFPI ${ }^{12}$ estabelece que "a execução dos projetos de pesquisa será acompanhada: I - pelo Departamento que deverá aprovar sua execução em assembleia, ou Conselho, dependendo de sua abrangência; II - por colegiado especial, em que todos os Departamentos envolvidos se representem". Diante disso, foi necessário verificar as informações dos projetos de pesquisa dos professores através do currículo Lattes, considerando que a chefia de departamento informou que não acompanha os projetos cadastrados.

A análise dos projetos cadastrados na UFPI contemplou pesquisas desenvolvidas no período de oito anos: de 2007 a 2014, sendo listados pela CGP quarenta projetos vinculados ao departamento de comunicação social e um ao programa de pós-graduação em comunicação. Analisaram-se somente os projetos vinculados ao departamento de comunicação social, pois graduação é o objeto desta pesquisa. No entanto, isso não significa que não há participação de alunos da pós-graduação em tais projetos, pois os professores responsáveis ministram aulas tanto na graduação quanto no mestrado.

A análise foi realizada a partir da descrição do projeto constante no Lattes dos professores e foram levados em consideração somente projetos cadastrados no setor responsável da IES.

Somente 32 projetos de pesquisa cadastrados foram analisados por atenderem os critérios estabelecidos. Os projetos foram divididos conforme mostrado na Tabela 1.

12. UNIVERSIDADE FEDERAL DO PIAUÍ. Resolução CONSUN/UFPI n' 21 , de 21 de setembro de 2000. Regimento Geral da Universidade Federal do Piauí. Teresina: UFPI, 2000. Disponível em: <http://www.leg.ufpi. br/arquivos/File/estatutos_e_regimentos/regimento_geral_ufpi.pdf>. Acesso em: 13 fev. 2017. 
comunicação \& educação • Ano XXIII • número 1 • jan/jun 2018

Tabela 1: Projetos de pesquisa vinculados a docentes do departamento de comunicação social analisados.

\begin{tabular}{c|c} 
Ano & Projetos cadastrados \\
\hline 2014 & 5 \\
\hline 2012 & 10 \\
\hline 2011 & 2 \\
\hline 2010 & 10 \\
\hline 2009 & 2 \\
\hline 2008 & 1 \\
\hline 2007 & 2 \\
\hline Total & 32 \\
\hline & Fonte: Elaborada pelos autores.
\end{tabular}

O levantamento mostrou que nenhum projeto traz a temática ambiental em seu título ou como abordagem principal. Dentro da divisão de especialização do jornalismo foram encontradas pesquisas que abordam a temática de jornalismo cultural, jornalismo esportivo, jornalismo opinativo e jornalismo político. Além disso, entre os projetos há análise realizada sobre a produção de notícias, análise dos meios de comunicação (rádio, jornal impresso, TV, internet), qualidade das práticas jornalística e construção da memória jornalística.

A partir da análise dos projetos cadastrados, percebeu-se que as pesquisas realizadas no curso de jornalismo da UFPI são próximas ou possuem continuidade e podem ser classificadas dentro de uma grande área, que, no caso do curso da UFPI, são as duas grandes áreas do mestrado: Processos e Práticas no Jornalismo e Mídia e Produção de Subjetividade. Ou seja, percebe-se que os docentes de comunicação da UFPI não possuem interesse em desenvolver pesquisas sobre a temática ambiental na IES.

Mesmo que as pesquisas realizadas tratem de assuntos interdisciplinares e ligados ao cotidiano do futuro profissional, percebe-se a existência de uma lacuna na formação dos discentes no eixo pesquisa sobre a temática da sustentabilidade, sendo necessário que os alunos que se interessam sobre o assunto busquem participar de projetos de pesquisa com docentes de outros cursos.

Ainda é importante informar que, dos dezoito docentes lotados no departamento de comunicação social da UFPI, somente nove cadastraram projetos de pesquisa no período analisado, ou seja, as pesquisas são realizadas por $50 \%$ do total de professores. Essa produção é um ponto negativo, considerando que os outros educadores poderiam realizar pesquisas sobre temáticas distintas e incluir a sustentabilidade no curso de jornalismo da UFPI.

Já quanto à produção de projetos de extensão, durante esta pesquisa foi necessário buscar informações a respeito dos projetos de extensão cadastrados pelo curso de jornalismo da UFPI através da pró-reitoria de extensão (PREX) e a confirmação das informações com o departamento de comunicação social da UFPI.

As informações obtidas na PREX foram do período de 2010 a 2014, sendo que os projetos são cadastrados por centro de ensino. Após ter em mãos informações 
sobre o centro de ciências da educação, no qual o curso está inserido, foram pesquisados projetos que tinham como coordenador algum professor lotado no departamento de comunicação. Dos cinco anos analisados, somente um projeto de extensão foi encontrado cujo cadastramento foi realizado em 2012 e trouxe como título "Jornal Comunitário".

Essas informações foram confirmadas nos currículos dos docentes, com isso, diferentemente do que acontece com projetos de pesquisa (mais de trinta projetos cadastrados), os de extensão ainda são raros. Quanto à temática ambiental, não se pode afirmar que está sendo abordada no projeto em execução.

Diante disso, é possível perceber a carência na formação dos alunos quanto à extensão, já que privilegia um pilar em detrimento de outro. Pode-se afirmar que a instituição cumpre sua função de forma desequilibrada, tornando um curso pendente para pesquisa.

\subsection{Universidade Estadual do Piauí}

A Uespi oferece dois cursos de jornalismo: um no campus Poeta Torquato Neto, localizado no bairro Pirajá, na cidade de Teresina; e outro no campus Professor Barros Araújo, localizado na cidade de Picos.

O curso de jornalismo do campus de Picos foi autorizado pelo conselho universitário (Consun) pela Resolução no 38, de 28 de janeiro de 2001, tendo sua primeira turma ingressado em 2002. Este foi o primeiro curso da área a ser instituído no interior do estado.

A análise dos projetos de pesquisa foi realizada com dados constantes nos currículos Lattes dos professores efetivos lotados nos cursos dos dois campi e foram identificados treze projetos de pesquisa elaborados. Na Tabela 2 pode ser percebida a distribuição desses projetos por ano.

Tabela 2: Quantitativos de projetos de pesquisa de professores de jornalismo do campus de Picos.

\begin{tabular}{c|c}
\hline Ano & Quantidade de projetos de pesquisa \\
\hline 2014 & 2 \\
\hline 2013 & 5 \\
\hline 2012 & 2 \\
\hline 2011 & 1 \\
\hline 2010 & 2 \\
\hline 2009 & 1 \\
\hline Total & 13 \\
\hline
\end{tabular}

Diante desses dados, percebeu-se que a elaboração de projetos de pesquisa na Uespi ainda é incipiente. Durante a análise, constatou-se que nenhum projeto tratou especificamente sobre a temática ambiental, demonstrando que não é o 
foco de interesse dos docentes. No entanto, cabe destacar a realização de um projeto que traz o regionalismo (local-global) como ponto, que busca analisar o lugar de fala (sertão piauiense) na internet (global), ultrapassando os limites físicos. Além disso, nesse mesmo projeto foi possível verificar mais dois pontos importantes que levam em consideração a temática ambiental: compromisso para a transformação das relações sociedade-natureza a partir de uma visão geradora de ação transformadora; e complexidade.

Ponto importante é a existência de participação dos alunos de graduação nos projetos de pesquisa, sendo 21 participantes dos projetos do campus de Teresina e 30 do campus de Picos, totalizando 51 discentes. Esse destaque se dá pelo fato de que a participação em projetos de pesquisa pode influenciar diretamente a escolha dos alunos sobre a temática a ser abordada nos trabalhos de conclusão de curso, já que como se percebeu o interesse deve partir diretamente do alunado.

Quanto a esse eixo, constatou-se que a produção em pesquisa ainda é pequena nos cursos de jornalismo da Uespi, o que pode ser justificado pelo fato de o corpo docente ser pequeno em cada campus e por ser composto por mestres com titulação recente. No entanto, docentes estão se qualificando e houve aumento do cadastramento de projetos a partir de 2013.

Diferente do que ocorre na UFPI, onde a maioria do corpo docente já possui titulação de doutor, nesta instituição a ascensão dos professores dificulta a produção de projetos de pesquisa como coordenadores. Além disso, a não abordagem nos projetos já existentes pode ser justificada pelo não conhecimento sobre a temática ou sobre não fazer parte de sua linha de pesquisa.

Já a atividade de extensão realizada na Universidade Estadual do Piauí deve ser planejada pelo Centro de Ensino e aprovada no Conselho de Ensino, Pesquisa e Extensão, o que é estabelecido no artigo $n^{\circ} 47$ do regimento geral da instituição ${ }^{13}$ :

A extensão será realizada sob a forma de programas, projetos, cursos, eventos e prestação de serviço, compreendendo trabalhos de natureza cultural, artística, técnica e científica em função do bem-estar individual e coletivo, e terá, como produto de suas ações, publicações e outros produtos acadêmicos.

Diante disso foram analisadas atividades de extensão realizadas pelos docentes devidamente registradas no currículo Lattes. Foram encontradas nove atividades de extensão, sendo que somente um dos projetos é uma parceria entre docentes dos dois campi. Na Tabela 3 é mostrado os tipos de atividades realizadas.

13. UNIVERSIDADE ESTADUAL DO PIAUÍ. Regimento Geral da Universidade Federal do Piauí. Teresina: UFPI, [200-?]. Disponivel em: <http:// www.uespi.br/site/wp-content/uploads/2013/07/ resolucao\% 20 e\%20regimento\%20da\%20uespi. pdf > Acesso em: 27 jan. 2017.

\section{Tabela 3: Atividades de extensão.}

\begin{tabular}{l|c}
\multicolumn{1}{c|}{ Atividade } & Quantidade \\
\hline Projeto de Extensão & 3 \\
\hline Curso & 3 \\
\hline Atividade de campo & 1 \\
\hline Evento científico & 2 \\
\hline Total & 9 \\
\hline \multicolumn{2}{|c|}{ Fonte: Elaborada pelos autores. }
\end{tabular}


Mais uma vez a temática ambiental não é tratada pelos docentes. Além disso, percebe-se que as atividades de extensão são realizadas por quatro docentes dos dois campi, ou seja, não há interesse da maioria dos professores em realizar trabalhos de extensão.

A falta de interesse por parte dos docentes na atividade de extensão e a pouca atividade de pesquisa realizada na Uespi mostram que, além de haver deficiência quanto à abordagem da temática ambiental durante todo o curso, há deficiência nas outras duas atividades, não somente no que diz respeito à abordagem da temática mas também na realização das atividades fins da universidade.

O que se percebe é um crescimento gradual dos cursos da Uespi, pois não demonstra estar consolidado nos dois últimos eixos. As dificuldades apresentadas pela instituição refletem na formação desses profissionais, seja na falta de laboratórios para aulas práticas ou na dificuldade de não haver formação nos eixos de pesquisa e extensão.

\section{CONSIDERAÇÕES FINAIS}

Diante dos dados apresentados, percebeu-se a existência de lacunas na formação dos jornalistas nas universidades públicas do Piauí não só quanto à questão ambiental como a possibilidades existentes aos alunos nos eixos pesquisa e extensão.

Quanto aos dados obtidos no eixo pesquisa, viu-se realidades distintas nas duas instituições, na UFPI a produção é realizada de forma mais efetiva do que na Uespi. No entanto, deve-se considerar que o curso daquela instituição já existe há 31 anos e há significativo número de docentes com titulação de doutor, enquanto na Uespi o corpo docente ainda está se qualificando e a maioria possui mestrado.

Por isso, quantitativamente, a UFPI apresenta pesquisa de forma mais desenvolvida, com mais de trinta projetos cadastrados nos oito anos pesquisados. $\mathrm{Na}$ Uespi foram cadastrados doze projetos em um período de seis anos. Contudo, percebe-se a ausência de preocupação com a temática ambiental na abordagem trazida nos projetos de pesquisa realizados nas duas instituições, pois nenhum projeto enfoca especificamente o meio ambiente como objeto de pesquisa.

Diante disso, é necessário trazer à tona questões que envolvem a temática ambiental, fazer que futuros jornalistas tenham conhecimento da temática, que problematizem a questão e possam ter visão crítica do tema para que no mercado de trabalho consigam lidar com as pautas, que estejam além do óbvio e que possam ter olhar crítico sobre a produção jornalística.

O eixo extensão é o mais carente de produção, pois percebeu-se que os docentes têm pouco interesse na produção desse tipo de projeto, principalmente na UFPI, onde foi localizado somente um projeto de extensão nos últimos cinco anos, o que foi ratificado na análise dos currículos Lattes dos docentes. Como 
nessa instituição os projetos partem de cada professor, é necessário construir uma cultura de elaboração de projetos de extensão, buscando dirimir a lacuna que historicamente existe. É preciso que a gestão institucional perceba a lacuna que esse pilar possui e exigir dos departamentos projetos voltados para a extensão. É necessário incentivo.

Na Uespi o que se verificou foi uma diversificação maior quanto à produção de atividade de extensão, incluindo organização de eventos e cursos, além de três projetos. Como há carência na produção, quando a pesquisa se volta para o meio ambiente como objeto de projetos, percebe-se que tal carência aumenta ainda mais.

Com isso é necessário que haja incentivo para a produção de trabalhos de extensão, considerando a importância desse eixo para o equilíbrio das universidades. Esse ponto traz como questão importante a interferência da gestão superior quanto ao desequilíbrio existente atualmente. A cultura institucional não muda em curto prazo, mas para que haja mudança é necessário o primeiro passo. Com maior produção no eixo extensão, a universidade incluiria a comunidade externa às atividades realizadas pela instituição.

\section{REFERÊNCIAS BIBLIOGRÁFICAS}

BRASIL. Ministério da Educação. Conselho Nacional de Educação. Resolução n ํㅜ 1, de 27 de setembro de 2013. Institui as Diretrizes Curriculares Nacionais para o curso de graduação em Jornalismo, bacharelado, e dá outras providências. Diário Oficial da União, Brasília, DF, 1ํo out. 2013. Seção 1, p. 26. Disponível em: <http://portal.mec.gov.br/index.php?option=com docman\&view=download\&alias=14242-rces001-13\&category_slug=setembro2013-pdf\&Itemid=30192>. Acesso em: 20 mar. 2017.

CAMPOS. Pedro Celso. Meio Ambiente: a sustentabilidade passa pela educação (em todos os níveis, inclusive pela mídia). Em Questão, Porto Alegre, v. 12, n. 2, p. 387-419, jun./dez. 2006. Disponível em: <http://seer. ufrgs.br/EmQuestao/article/view/42/14>. Acesso em: 27 fev. 2017.

LEFF, Enrique. Saber ambiental: sustentabilidade, racionalidade, complexidade, poder. 9. ed. Petrópolis: Vozes, 2012.

MARCOMIN, Fátima Elizabeti; SILVA, Alberto Dias Vieira. A universidade sustentável: alguns elementos para a ambientalização do ensino superior a partir da realidade brasileira. In: CONGRESSO INTERNACIONAL DE EDUCAÇÃO AMBIENTAL DOS PAÍSES LUSÓFONOS E GALICIA, 1., 2007, Santiago de Compostela. Anais... Santiago de Compostela: Ceida, 2007. p. 1-16.

MORAES, Maria Cândida. O paradigma educacional emergente. 16. ed. Campinas: Papirus, 2011. 
A temática ambiental nos projetos de pesquisa e extensão do curso de jornalismo das universidades do Piauí - Elinara Soares Barros de Sousa et al.

MORIN, Edgar. Os sete saberes necessários à educação do futuro. 8. ed. São Paulo: Cortez, 2003.

O pensamento complexo, um pensamento que pensa. In: MORIN, Edgar; LE MOIGNE, Jean-Louis. A inteligência da complexidade. São Paulo: Peirópolis, 2000. p. 197-213.

RAMOS, Roberto. A educação e o conhecimento: uma abordagem complexa. Educar, Curitiba, n. 32, p. 75-86, 2008.

UNIVERSIDADE ESTADUAL DO PIAUÍ. Regimento Geral da Universidade Federal do Piauí. Teresina: UFPI, [200-?]. Disponível em: <http://www.uespi. $\mathrm{br} /$ site/wp-content/uploads/2013/07/resolucao \% 20e\%20regimento\% 20 da\%20uespi.pdf> Acesso em: 27 jan. 2017.

UNIVERSIDADE FEDERAL DO PIAUÍ. Resolução CONSUN/UFPI nº 21, de 21 de setembro de 2000. Regimento Geral da Universidade Federal do Piauí. Teresina: UFPI, 2000. Disponível em: <http://www.leg.ufpi.br/ arquivos/File/estatutos_e_regimentos/regimento_geral_ufpi.pdf $>$. Acesso em: 13 fev. 2017. 
